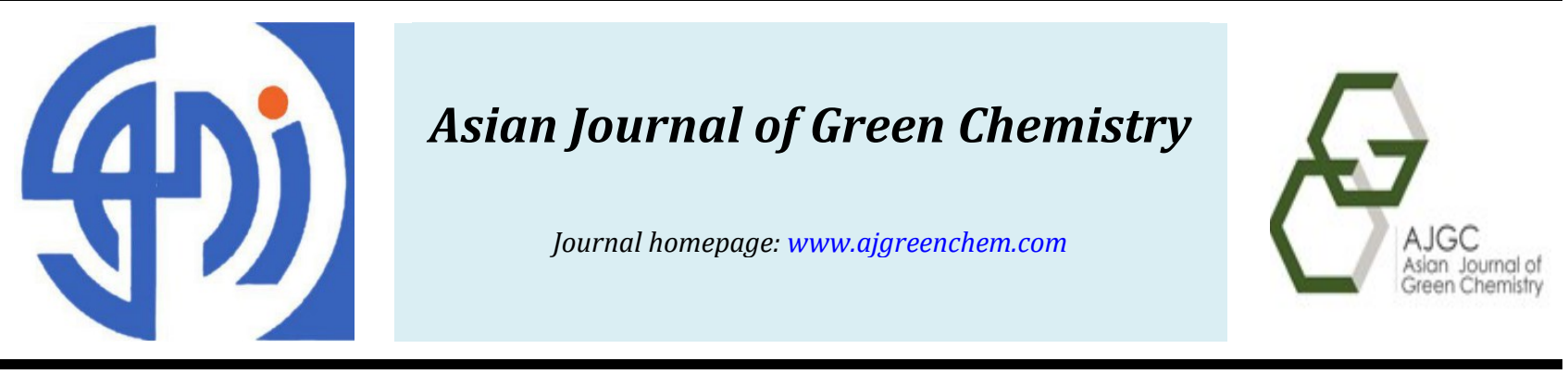

Original Research Article

\title{
Solvent-free synthesis for imidazole-1-yl-acetic acid hydrochloride: an intermediate for zoledronic acid
}

\author{
Chandra Kant Belwal* (D), Jaimin Patel
}

Research and Process Development, Sterling Biotech Ltd., Masar, Jambusar State Highway, Vadodara, Gujarat, India, Pin code391421

\section{ARTICLE INFORMATION}

Received: 12 October 2018

Received in revised: 20 October 2018

Accepted: 29 October 2018

Available online: 19 January 2019

DOI: $10.33945 /$ SAMI/AJGC.2019.4.5

\section{KEYWORDS}

Imidazol-1-yl-acetic acid hydrochloride

$N$-alkylation

Solvent-free

Hydrolysis

Zoledronic acid

\begin{abstract}
In the present work, a convenient and environmentally-friendly protocol for the preparation of imidazol-1-yl-acetic acid hydrochloride is discussed via solvent-free $\mathrm{N}$-alkylation of imidazole by tert-butyl chloroacetate, the obtained imidazol-1-yl-acetic acid tert-butyl ester was hydrolyzed in water and treated with hydrochloric acid to obtain the imidazol-1-yl-acetic acid hydrochloride in good yields. Unlike the previously reported methods, this two step process was completely free from the use of hazardous solvents. In addition, it revealed high yield and characterized using a simple and easy work-up procedure. The imidazol-1-yl-acetic acid hydrochloride that produced in this study was converted into zoledronic acid monohydrate, which can be utilized in medicinal aplications.

(C) 2019 by SPC (Sami Publishing Company), Asian Journal of Green Chemistry, Reproduction is permitted for noncommercial purposes.
\end{abstract}




\section{Graphical Abstract}

$$
\mathrm{N}_{-\mathrm{NH}}^{\mathrm{N}}+\mathrm{Cl} \overbrace{\mathrm{O}}^{\mathrm{O}}\rangle
$$

(2) tert-butyl chloroacetate<smiles>CCOC(=O)Cn1ccnc1</smiles>

(3)

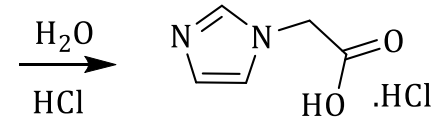

(4)

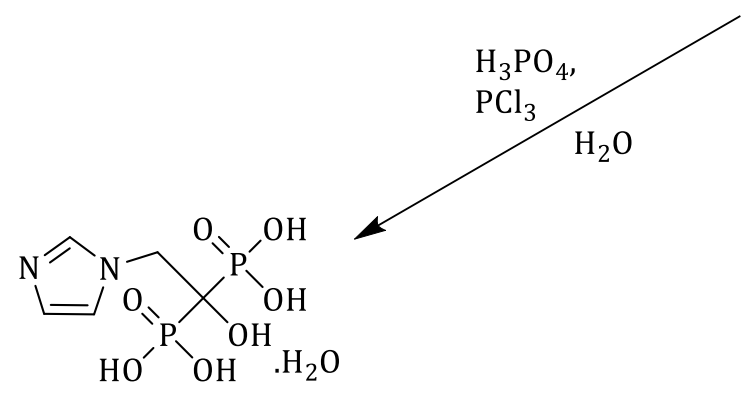

(1)

\section{Introduction}

Imidazol-1-yl-acetic acid hydrochloride (4) is a key intermediate for synthesis of (1-hydroxy-2imidazole-l-yl-phosphonoethyl)-bisphosphonic acid (Zoledronic acid) (1, Scheme 1), a third generation and a very popular bisphosphonate derivative. Zoledronic acid is used to treat some diseases including osteoporosis, high blood calcium due to cancer, bone breakdown due to cancer, and Paget's disease of bone. Zoledronic acid (1) is used along with cancer chemotherapy; however, it neither suppresses nor stops cancer spreading. Zoledronic acid is used to treat bone related implications in patients who are suffering from cancer. It is widely used as a bone resorption inhibitor. It may decrease the amount of calcium released from bones into the blood [1-4].

In the literature, various routes for preparation of the imidazol-1-yl-acetic acid hydrochloride (4) and zoledronic acid have been reported [5-9]. All the published procedures require environmentally hazardous solvents such as dichloromethane (DCM) [5], mixture of DMF and toluene [6, 7], ethyl acetate [8], and DMF [9], for $N$-alkylation of imidazole (2) with haloester. In some studies they have used solvents for reaction, for extraction, isolation, and crystallization.

To minimize the use of environmentally hazardous solvents, we have developed a convenient and practical solvent free protocol for the preparation of imidazol-1-yl-acetic acid hydrochloride (4). Our two step process for the preparation of imidazol-1-yl-acetic acid hydrochloride (4) involves solventfree reaction of imidazole (2) with tert-butyl chloroacetate at the presence of suitable base and isolation of formed imidazol-1-yl-acetic acid tert-butyl ester (3) from water. In the second step, 
imidazol-1-yl-acetic acid tert-butyl ester (3) was hydrolyzed to imidazol-1-yl-acetic acid followed by a treatment with hydrochloric acid to get imidazol-1-yl-acetic acid hydrochloride (4).

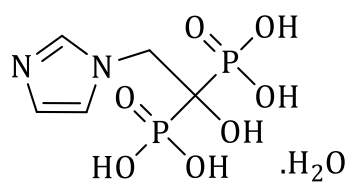

(1)

Scheme 1. Zoledronic acid monohydrate

\section{Experimental}

\section{Materials and Methods}

Laboratory grade reagents were used without further purification. The progress of the reactions was monitored by TLC (10\% methanol in chloroform, iodine visualization) and chromatographic purity of isolated solids was checked by HPLC. The HPLC results were recorded qualitatively, and the details of the chromatographic conditions are summarized in Table 1. All the synthesized compounds were characterized using ${ }^{1} \mathrm{H}$ NMR, ${ }^{13} \mathrm{C}$ NMR, IR, and MS spectra. ${ }^{1} \mathrm{H}$ NMR and ${ }^{13} \mathrm{C}$ NMR spectra were recorded on a Bruker Avance 500 spectrometer (500 MHz) at $500 \mathrm{MHz}\left({ }^{1} \mathrm{H}\right)$ and $125 \mathrm{MHz}\left({ }^{13} \mathrm{C}\right)$. IR spectra were measured on PerkinElmer spectrum 100 FT-IR spectrometer. The mass spectra (ES ${ }^{+}$ mode) were acquired on waters Q-Tof premier micromass. The melting points were recorded using the BUCHI melting point apparatus.

Table 1. Chromatographic conditions to check purity of isolated solids.

$\begin{array}{lc}\text { Parameters } & \text { Conditions } \\ \text { Instrument } & \text { Waters Alliance HPLC System } \\ \text { Column } & \text { Waters X-Bridge Phenyl, } 4.6 \times 250 \mathrm{~mm}, 5 \mu \mathrm{m} \\ \text { Detection } & \mathrm{UV} 220 \mathrm{~nm} \\ \text { njection volume } & 10 \mu \mathrm{L} \\ \text { Flow rate } & 0.8 \mathrm{~mL} / \mathrm{min} \\ \text { Mobile phase } & \text { Buffer + Methanol in a ratio of } 20 \text { and } 1\end{array}$

Buffer preparation: $2 \mathrm{~mL}$ triethylamine in to $100 \mathrm{~mL}$ water and adjust $\mathrm{pH}$ to 3.0 with phosphoric acid

Run time

$30 \mathrm{~min}$ 
The powdered imidazole (2) (20.0 g, $0.29 \mathrm{~mol}$ ) and tert-butyl chloroacetate (44.2 g, $0.29 \mathrm{~mol}$ ) were added to $\mathrm{K}_{2} \mathrm{CO}_{3}(50.7 \mathrm{~g}, 0.37 \mathrm{~mol})$ at $0-5{ }^{\circ} \mathrm{C}$, then, it was slowly heated up to $60{ }^{\circ} \mathrm{C}$ and stirred for 4-6 h. After the reaction was completed, (as indicated by TLC, 10\% methanol in chloroform, iodine visualization), the reaction mass was cooled down to $20-25{ }^{\circ} \mathrm{C}$ and $100 \mathrm{~mL}$ of water was added and the mixture stirred for 5-10 min. Filtration and air drying of the resulting solid afforded the title compound (3) as a shiny white crystalline solid (35.5 g, 66\%). mp 111-113.6 ${ }^{\circ} \mathrm{C}$, IR $(\mathrm{KBr})\left(v_{\max } / \mathrm{cm}^{-}\right.$ 1): 3453, 3111, 2981, 2874, 1739, 1512, 1230, 1148, 1079, 742, and 662. ${ }^{1 H}$ NMR (500 MHz, DMSO$\left.\mathrm{d}_{6}\right): \delta 1.41(\mathrm{~s}, 9 \mathrm{H}), 4.82(\mathrm{~s}, 2 \mathrm{H}), 6.86(\mathrm{~s}, 1 \mathrm{H}), 7.11(\mathrm{~s}, 1 \mathrm{H}), 7.58(\mathrm{~s}, 1 \mathrm{H}) .{ }^{13} \mathrm{C}$ NMR (125 MHz, DMSO-d6): $\delta 28.04,48.26\left(\mathrm{CH}_{2}\right.$, confirmed by dept 135 spectra), 82.34, 121.29, 127.99, 138.59, 167.99. MS (m/z) $183.11[\mathrm{M}+1]$.

\section{Synthesis of imidazol-1-yl-acetic acid hydrochloride (4)}

A mixture of imidazol-1-yl-acetic acid tert-butyl ester (3) (20.0 g, $0.11 \mathrm{~mol})$ and water (200 mL) was heated to $90-95{ }^{\circ} \mathrm{C}$ and stirred for $2 \mathrm{~h}$. The clear solution indicated that the reaction was completed. After completion of reaction, it was cooled down to $20-25{ }^{\circ} \mathrm{C}$, and $10 \mathrm{~mL}$ of the concentrated hydrochloric acid was added and stirred for $30 \mathrm{~min}$. Complete evaporation of reaction mass under reduced pressure afford the title compound (4) as a white solid (16.6 g, 93\%). Chromatographic purity 99.47\%; $\mathrm{HCl}$ content of $22.78 \%$ (cal 22.42\%); mp 200.3-202.3 ${ }^{\circ} \mathrm{C}$, IR (KBr) $\left(v_{\max } / \mathrm{cm}^{-1}\right): 3485,3159,3078,2956,2827,1732,1548,1406,1222,1178,1080,763$, and 626. ${ }^{1} \mathrm{H}$ NMR (500 MHz, DMSO-d $_{6}$ : $\delta 4.76$ (s, 2H, -CH2), 6.88 (s, 1H), $7.12(\mathrm{~s}, 1 \mathrm{H}), 7.64(\mathrm{~s}, 1 \mathrm{H}) .{ }^{13} \mathrm{C}$ NMR $(125$ MHz, DMSO-d $\left.{ }_{6}\right): \delta 51.61\left(\mathrm{CH}_{2}\right.$, confirmed by dept 135 spectra $), 119.18,122.82,135.26,172.41$. MS $(\mathrm{m} / \mathrm{z}) 127.04[\mathrm{M}+1]$.

\section{Synthesis of zoledronic acid monohydrate (1)}

To a suspension of imidazol-1-yl-acetic acid hydrochloride (4) (10.0 g, $0.06 \mathrm{~mol}$ ) and orthophosphoric acid (85\%) (18.3 mL, $0.27 \mathrm{~mol})$ in 1,4-dioxane (50 mL) was added phosphorous oxychloride ( $34.7 \mathrm{~mL}, 0.39 \mathrm{~mol}$ ) at $80-85{ }^{\circ} \mathrm{C}$ over a period of $2 \mathrm{~h}$, then, heated to $90-95{ }^{\circ} \mathrm{C}$ for $4 \mathrm{~h}$. The reaction mass was cooled down to $60-65^{\circ} \mathrm{C}$, and $100 \mathrm{~mL}$ of water was slowly added to the mixture. The temperature of the mixture was increased up to $95-100{ }^{\circ} \mathrm{C}$ and it was stirred for $4 \mathrm{~h}$. Reaction mass was treated with $0.5 \mathrm{~g}$ activated charcoal for $30 \mathrm{~min}$ and filtered through a celite bed at the same temperature. The filtrate was then cooled down to room temperature and $400 \mathrm{~mL}$ of methanol was added to the mixture. It was stirred for $2 \mathrm{~h}$, and the precipitated solid was filtered, washed with methanol $(20 \mathrm{~mL})$, and dried under vacuum for $6 \mathrm{~h}$ at $25-30{ }^{\circ} \mathrm{C}$ to afford the title compound (1) as a white crystalline solid (15 g, 84\%). Chromatographic purity 99.70\%; moisture 
content 6.77\% w/w (calculated 6.62\%, monohydrate); mp $238.2^{\circ} \mathrm{C}(\mathrm{dec}), \mathrm{IR}(\mathrm{KBr})\left(\mathrm{v}_{\max } / \mathrm{cm}^{-1}\right): 3446$ $(\mathrm{O}-\mathrm{H}), 1580(\mathrm{C}=\mathrm{N})$, and $1279(\mathrm{P}=0) .{ }^{1} \mathrm{H}$ NMR (500 MHz, $\left.\mathrm{D}_{2} \mathrm{O}\right): \delta 4.55\left(\mathrm{t}, 2 \mathrm{H},-\mathrm{CH}_{2}\right), 7.23(\mathrm{~s}, 1 \mathrm{H}), 7.38$ $(\mathrm{s}, 1 \mathrm{H}), 8.58(\mathrm{~s}, 1 \mathrm{H}) \cdot{ }^{13} \mathrm{C}$ NMR $\left(125 \mathrm{MHz}, \mathrm{D}_{2} \mathrm{O}\right): \delta 52.34\left(\mathrm{CH}_{2}\right.$, confirmed by dept 135 spectra), 118.18, 123.84, 135.77, 172.41. MS (m/z) 273.05 [M+1].

\section{Results and Discussion}

Synthesis of imidazol-1-yl-acetic acid hydrochloride (4), a key intermediate in the synthesis of zoledronic acid (1), involves two synthetic steps, $\mathrm{N}$-alkylation of imidazole to get imidazol-1-ylacetate and hydrolysis of imidazol-1-yl-acetate to get imidazol-1-yl-acetic acid hydrochloride (4). The most common and widely used method for $\mathrm{N}$-alkylation of imidazole is the alkylation at the presence of a base in a solvent medium.

Synthesis of imidazol-1-yl-acetic acid has been reported in some studies [5-9]. However, $\mathrm{N}$ alkylation reactions were carried out in the solvent medium for the extraction, isolation, and crystallization. According to the synthetic method reported by Yadav et al. [5], methyl imidazol-1-ylacetate was synthesized by the addition of methyl chloroacetate to a mixture of imidazole, potassium carbonate $\left(\mathrm{K}_{2} \mathrm{CO}_{3}\right)$ and potassium iodide (KI) in the media of dichloromethane (DCM), resulting imidazole-1-yl-acetate which was de-esterified in water and isolated from methanol, using solvents in both steps. Synthetic method by Pulla Reddy et al. [6] include addition of methyl chloroacetate to a mixture of imidazole, potassium carbonate $\left(\mathrm{K}_{2} \mathrm{CO}_{3}\right)$ and tetrabutylammonium bromide (TBAB) in the solvent media comprised of DMF and toluene, after the completion of the reaction, it was worked up by extraction in ethyl acetate and finally evaporation of ethyl acetate to afford ester intermediate which was hydrolyzed in water. Another method by Pulla Reddy et al. [7] involved the reaction of methyl chloroacetate with imidazole at the presence of potassium carbonate $\left(\mathrm{K}_{2} \mathrm{CO}_{3}\right)$ and potassium iodide (KI) in a mixture of solvents including, DMF and toluene followed by hydrolysis to afford imidazol-1-yl-acetic acid which was then converted to its hydrochloride salt. Santosh Kumar Singh et al. [8] describe the reaction of tert-butyl chloroacetate (TBCA) with imidazole at presence of the potassium carbonate $\left(\mathrm{K}_{2} \mathrm{CO}_{3}\right)$ in the media of ethyl acetate and crystallization in hexane followed by non-aqueous ester cleavage using titanium chloride $\left(\mathrm{TiCl}_{4}\right)$ in the media of dichloromethane and isopropanol (IPA) to afford imidazol-1-yl-acetic hydrochloride salt, thus using four solvents in two step process. Javad Mokhtari Aliabad et al. [9] described a process for the preparation of benzyl-2(1H-imidazole-1-yl)acetate by the reaction of benzyl-2-chloroacetate and imidazole in the media of DMF using $\mathrm{K}_{2} \mathrm{CO}_{3}$ as base, formed benzyl-2-(1H-imidazole-1-yl) acetate was then converted to imidazol-1-yl-acetic acid by deprotection of the benzyl group with hydrochloric acid. 
Various solvents have been used for extraction, isolation, and crystallization of the products, which are dangerous to the environment. In this research study, we have developed a very efficient and solvent-free process for the preparation of imidazole-1-yl-acetic acid hydrochloride (4). Our two step process (Scheme 2) involve preparation of imidazol-1-yl-acetic acid tert-butyl ester (3) by reacting imidazole (2) with tert-butyl chloroacetate (TBCA) in the presence of suitable base in solvent-free medium and isolation of imidazol-1-yl-acetic acid tert-butyl ester (3) by adding water to the reaction mixture, in second step imidazol-1-yl-acetic acid tert-butyl ester (3) is hydrolyzed in to imidazol-1-yl-acetic acid followed by treatment with hydrochloric acid to get imidazol-1-yl-acetic acid hydrochloride (4).

The aim of this study was to develop environmentally-friendly synthesis of imidazol-1-yl-acetic acid tert-butyl ester (3) and its conversion to imidazol-1-yl-acetic acid hydrochloride (4) without using any solvent in entire two step process. Imidazol-1-yl-acetic acid tert-butyl ester (3) was synthesized by reacting the imidazole (2) with an equimolar amount of tert-butyl chloroacetate (TBCA) at the presence of the powdered potassium carbonate without using any solvent medium. The easy workup procedure is another salient feature of our process, after the completion of reaction (2 to 3) reaction mass was cooled down to room temperature and water was added to it, imidazol-1yl-acetic acid tert-butyl ester (3) crystallize out as shiny white crystals, while unreacted imidazole (2), unreacted base and inorganic by products remains with water, thus avoiding extraction, solvent evaporation and solvent crystallization steps of earlier reported methods. Imidazol-1-yl-acetic acid tert-butyl ester (3) was then hydrolysed by heating in water and formed acid was treated with hydrochloric and converted to imidazol-1-yl-acetic acid hydrochloride (4).

Imidazole undergoes di-alkylation reacted with tert-butyl chloroacetate and formed di-acid impurity 4a (Scheme 3). It is reported [10] that, formation of di-acid impurity (4a) resulted from the nature of the condensation of haloester with imidazole. According to reference [10] weak bases such as amines or alkali metal carbonates are less suitable for this reaction and strong bases like potassium tertiary butoxide are preferred. Our study suggested that, the molar equivalent of the haloester is responsible for formation of the di-acid impurity (4a).

Experiments were carried out with different molar equivalent of tert-butyl chloroacetate (Table 2) keeping same base ( $\mathrm{KOH})$, It was observed that one molar equivalent of tert-butyl chloroacetate substantially yield pure imidazol-1-yl-acetic acid hydrochloride (4) with di-acid impurity (4a) less than $0.50 \%$, increasing molar equivalent of tert-butyl chloroacetate to 1.10 results in $4.49 \%$ di-acid 


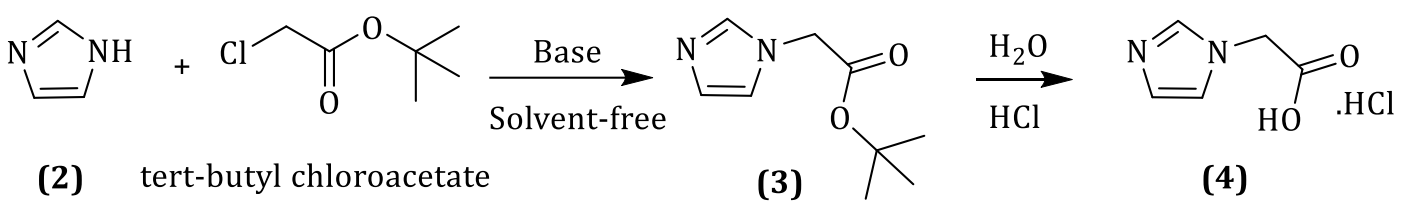

Scheme 2. Solvent-free synthesis of imidazol-1-yl-acetic acid hydrochloride

Scheme 3. Di-acid impurity of imidazol-

1-yl-acetic acid

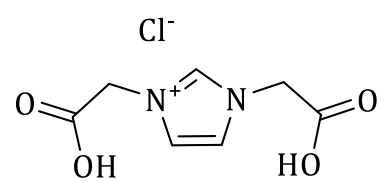

(4a)

Table 2. Solvent-free reaction of imidazole (2) with different mol eq. of TBCA

\begin{tabular}{cccccc}
2 (mol) & TBCA (mol/mol eq.) & KOH (mol) & \multicolumn{3}{c}{ HPLC purity after hydrolysis (\%) } \\
0.15 & $0.30 / 2.00$ & 0.30 & 22.69 & 0.50 & $\mathbf{4 a}$ \\
0.15 & $0.19 / 1.25$ & 0.23 & 43.74 & 2.68 & 52.50 \\
0.15 & $0.17 / 1.10$ & 0.19 & 94.63 & 0.65 & 4.49 \\
0.15 & $0.15 / 1.00$ & 0.19 & 99.41 & 0.14 & 0.34 \\
\hline
\end{tabular}

impurity (4a) in hydrolyzed product, further increase in the molar equivalent of tert-butyl chloroacetate to 1.25 and 2.00 results in the formation of $52.50 \%$ and $72.84 \%$ di-acid impurity (4a) respectively. Experiments were also carried out with different bases keeping one molar equivalent of tert-butyl chloroacetate (Table 3), di-acid impurity (4a) was found less than $0.50 \%$ in all the cases indicating role of tert-butyl chloroacetate quantity for the formation of di-acid impurity (4a).

Imidazol-1-yl-acetic acid hydrochloride (4) prepared by solvent-free process was converted to zoledronic acid monohydrate (1) by reacting with orthophosphoric acid and phosphorous oxychloride in the media of 1,4-dioxane (Scheme 4). This reaction was tried in numbers of solvents, but 1,4-dioxane was chosen because unlike the other solvents reaction mass the 1,4-dioxane was less sticky and easily stirable, which leads the complete conversion. Unlike chlorobenzene (widely used solvent for this reaction) 1,4-dioxane need not to be separated/decanted after reaction.

Table 3. Solvent-free reaction of imidazole (2) and TBCA with different bases.

\begin{tabular}{ccccccc}
2 & TBCA & Base $(1.25$ & \multicolumn{2}{c}{ Yield (\%) } & \multicolumn{2}{c}{ HPLC purity after hydrolysis (\%) } \\
(mol) & (mol) & mol eq.) & $\mathbf{2}$ to $\mathbf{3}$ & $\mathbf{3}$ to $\mathbf{4}$ & $\mathbf{4}$ & $\mathbf{2}$
\end{tabular}




$\begin{array}{llcccccc}0.15 & 0.15 & \mathrm{KOH} & 45 & 91 & 99.41 & 0.14 & 0.34 \\ 0.15 & 0.15 & \mathrm{~K}_{2} \mathrm{CO}_{3} & 66 & 93 & 99.47 & 0.12 & 0.39 \\ 0.15 & 0.15 & \text { TEA } & 49 & 90 & 99.15 & 0.27 & 0.42 \\ 0.15 & 0.15 & \text { DIPEA } & 45 & 90 & 99.11 & 0.32 & 0.48\end{array}$

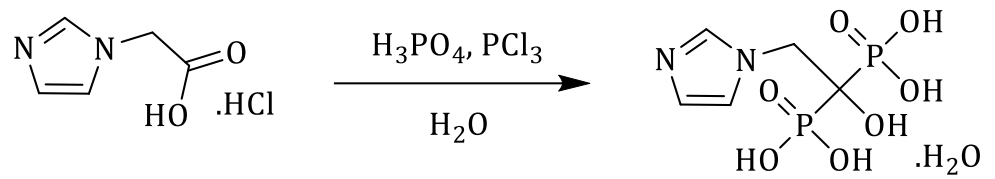

Scheme 4. Synthesis of zoledronic acid monohydrate

\section{Conclusion}

An efficient and green, 2-step synthesis of Imidazol-1-yl-acetic acid hydrochloride (an intermediate for Zoledronic acid) was developed by solvent-free $\mathrm{N}$-alkylation of Imidazole using tertbutyl chloroacetate followed by aqueous hydrolysis and hydrochloride salt formation. The method offers several advantages which include less process time, high yield, simple work-up procedure and formation of substantially pure compound.Equimolar ratio of tert-butyl chloroacetate and Imidazole (2) was found optimum for the synthesis of Imidazol-1-yl-acetic acid tert-butyl ester (3), aqueous hydrolysis and hydrochloride salt formation of which afforded Imidazol-1-yl-acetic acid hydrochloride (4) having di-acid impurity (4a) less than 0.50\%. Imidazol-1-yl-acetic acid tert-butyl ester (3) can be isolated simply by suspending reaction mass in water followed by filtration which prevents solvent evaporation, recrystallization and drying steps of conventional methods. Imidazol1-yl-acetic acid hydrochloride (4) produced by the described method was converted into Zoledronic acid monohydrate (1) of $99.70 \%$ chromatographic purity

\section{Disclosure Statement}

No potential conflict of interest was reported by the authors.

\section{Orcid}

Chandra Kant Belwal (iD 0000-0001-6352-204X

\section{References}

[1]. Sorbera L.A., Rabasseda X., Castaner J. Drugs Fut., 2000, 25:259 
[2]. Brown D.L., Robbins R. J. Clin. Pharmacol., 1999, 39:651

[3]. Cheer S.M., Noble S. Drugs, 2001, 61:799

[4]. Ratrout S.S., Al Sarabi A.M., Sweidan K.A. Pharm. Chem. J., 2015, 48:835

[5]. Yadav R.P., Shaikh Z.G., Mukarram S.M.J., Kumar Y. European Patent, EP1963345A2, 2008

[6]. Muddasani P.R., Vattikuti U.R., Kagitha R.R., Nannapaneni V.C. Indian Patent, 202056, 2007

[7]. Muddasani P.R., Vattikuti U.R., Nannapaneni V.C. PCT Int. Pat. Appl., W02005/063717, 2005

[8]. Singh S.K., Manne N., Ray P.C., Beilstein P.M. J. Org. Chem., 2008, 4:42

[9]. Aliabad J.M., Hosseini M., Yavari I., Rouhani M. The 20 th International Electronic Conference on Synthetic Organic Chemistry.

[10]. Martin K., Benes M., Pis J. European Patent, EP 2192126 A1, 2010

How to cite this manuscript: Chandra Kant Belwal*, Jaimin Patel. Solvent-free synthesis for imidazole-1-yl-acetic acid hydrochloride: an intermediate for zoledronic acid. Asian Journal of Green Chemistry, 3(4) 2019, 483-491. DOI: 10.33945/SAMI/AJGC.2019.4.5 